Jurnal Biologi dan Pembelajarannya, Vol 6 No 2, Oktober 2019. Pp: 15-16

e-ISSN: $2406-8659$

\title{
INVENTARIS JAMUR KONSUMSI DAN BERACUN DI PERKEBUNAN SAWIT KABUPATEN MUSI RAWAS
}

\author{
Eka Lokaria, Ivoni Susanti, Mareta Widiya \\ STKIP PGRI Lubuklinggau \\ Email: ekalokaria87@gmail.com
}

\begin{abstract}
Abstrak
Tujuan penelitian mengetahui jenis-jenis jamur yang dapat dikonsumsi dan beracun di PT Bina Sains Cemerlang, Kabupaten Musi. Metode yang digunakan observasi, wawancara, dokumentasi dan eksplorasi kemudian dianalisis secara deskriptif kualitatif. Hasil penelitian menunjukkan jenis jamur yang dapat dimakan yakni Poliotha mutabilis, Coprinus comatus, Schizophyllum commune, Pleorotus ostreatus, Volvarielle volvacea dan Auricularia polytricha. Jenis jamu beracun yakni: Hidnum repandum, Trametes versicolor, Mycena hiemalis, Lentinus conatus, Marasmius remealis, Dacryopinax spathularia, Polyporus squamosus, Pycnoporus annabarinus, Fuligo septica dan Cortinarius sanguenius
\end{abstract}

Kata kunci- Inventraisasi, Jamur Konsumsi, Jamur Beracun

\section{PENDAHULUAN}

Jamur makroskopis sebagian besar termasuk divisi Basidiomycota dan Ascomycota. Ekologis jamur dapat mempengaruhi keseimbangan ekosistem karena jamur pengurai utama yang menjaga ketersedian nutrien anorganik yang sangat penting bagi pertumbuhan tumbuhan di dalam ekosistem. Diantara jamur yang tumbuh secara alami, ada beberapa jamur yang bisa dikonsumsi dan berkhasiat obat [1]. Menurut Darwis,dkk. (2011), jamur dapat ditemukan pada berbagai substrat, antara lain batang tumbuhan mati, tempat basah atau kaya akan zat organik dan juga dapat ditemukan pada pohon mati, kotoran ternak, tanah, sampah dan sisa-sisa hasil penguraian bahan organik [2].

Jamur merupakan tumbuhan yang tergolong dalam eukarotik tetapi tidak memiliki klorofil, namun memiliki spora. Jamur pada umumnya hidup ditempat yang lembab dan bersifat saprofit. Tubuh jamur kebanyakan berbentuk seperti payung, memiliki akar, batang, dan tedung, memiliki kromatofora sehinggga tidak jarang memiliki warna mencolok. Penenan jamur ke dalam kelompok yang dapat dikonsumsi atau beracun cukup sulit dilakukan. Salah satu cara untuk menentukanya adalah dengan mengetahui secara tepat spesies dari jamur tersebut [3]. Menurut Chew (2008), jamur beracun biasanya berwarna sangat mencolok, tidak terdapat gigitan dari organisme lain dan dan biasanya berbau busuk karena mengandung senyawa sulfide [4].

PT Bina Sains merupakan perusahaan yang bergerak di bidang perkebunan kelapa sawit di kabupaten Musi Rawas dengan luas $6.513 \mathrm{Ha}$. Berdasarkan hasil observasi jamur pada umumnya ditemukan di janjang kosong kelapa sawit, pelepah, batang pohon yang telah lapuk dan di tanah yang gembur. Pendaatan terkait jamur yang ditemukan dan tergolong dalam jamur yang dapat dikonsumsi atau tidak belum ditemukan untuk itu perlu dilakukan inventaris jamur di kabupaten Musi Rawas.

\section{METODE PENELITIAN}

Pengambilan sampel jamur dilakukan dengan metode "purposive area sampling" dengan memilih lokasi perbukitan dan dataran yang masing-masing terdiri dari 3 divisi. Dengan memperhatikan ciri-ciri seperti warna tubuh buah, bilah, volva, cincin, tudung, tangkai, habitat/substrat tanah atau batuan, cara melekat pada substrat, aroma. Sampel jamur yang telah diperoleh dimasukkan ke dalam botol koleksi yang telah diisi alkohol $70 \%$ dan gliserin. Sampel dibawa ke laboratorium biologi STKIP PGRI Lubuklinggau untuk diindetifikasi lebih lanjut.

Pengukuran faktor fisik lingkungan seperti suhu, kelembaban dan pH dilakukan di sekitar pengambilan sampel.Alat yang digunakan adalah mikroskop binokuler, mikrometer, psycrometer, altimeter, pH meter, soil tester, thermometer, kaca objek, kaca penutup, vortex, plastik, oven, tabung reaksi, GPS, buku panduan identifikasi, botol koleksi, kertas label, stoples serta pinset. Beberapa bahan yang digunakan yaitu alkohol $70 \%$, gliserin, aquabides dan aquades. 
Jurnal Biologi dan Pembelajarannya, Vol 6 No 2, Oktober 2019. Pp: 15-16

e-ISSN: $2406-8659$

HASIL DAN PEMBAHASAN

\begin{tabular}{clcccc}
\hline \multirow{2}{*}{ Divisi } & \multicolumn{1}{c}{ Jenis } & \multicolumn{2}{c}{ Lokasi } & \multicolumn{2}{c}{ Jenis Jamur } \\
\cline { 2 - 5 } Basidiomycota & Poliotha mutabilis & Perbukitan & Dataran & Konsumsi & Beracun \\
& Hidnum repandum & + & + & + & - \\
& Coprinus comatus & - & + & - & + \\
& Schizophyllum commune & - & + & + & - \\
& Trametes versicolor & - & + & + & - \\
& Pleorotus ostreatus & + & + & - & + \\
& Volvariella volvaceae & + & + & + & - \\
& Marasmius ramealis & + & - & + & - \\
& Polyporus squamosus & - & + & - & + \\
& Lentinus connatus & - & + & - & + \\
& Cortinarius sanguenius & - & + & - & + \\
& Pycnoporus annabarinus & + & + & - & + \\
& Auricularia polytricha & + & - & + & - \\
& Mycena hiemalis & + & + & - & + \\
& Dacryopinax spathularia & - & + & - & + \\
& Fuligo septica & + & - & - & + \\
\hline
\end{tabular}

Kawasan dataran rendah ditemukan paling banyak jenis jamur makroskopis. Hal ini dikarenakan adanya perbedan faktor abiotik saat proses penelitian dilaksanakan. Daerah perbukitan habitatnya mengalami perubahan diakibatkan penebangan batang kelapa sawit dan proses ini baru berlang sementara dataran rendah daerah pembungan janjangan kosong kelapasawit sehingga lingkungan lembab dan tidak terkenan sinar matahari secara langsung sehingga disukai oleh pertumbuhan jamur. Jenis jamur yang dapat dikonsumsi yakni Poliotha mutabilis, Coprinus comatus, Schizophyllum commune, Pleorotus ostreatus, Volvarielle volvacea dan Auricularia polytricha. Jenis jamu beracun yakni: Hidnum repandum, Trametes versicolor, Mycena hiemalis, Lentinus conatus, Marasmius remealis, Dacryopinax spathularia, Polyporus squamosus, Pycnoporus annabarinus, Fuligo septica dan Cortinarius sanguenius. Enam jenis jamur konsumsi ditemukan pada janjangan kelapa sawit dan paling banyak ditemukan di daerah dataran dengan temperatur berkisar $28-31^{\circ} \mathrm{C}$ dengan $\mathrm{pH}$ 6,5-7,4 dengan kelembapan 71-79\%. Untuk daerah dataran tinggi temperatur rata-rata berkisar $29-33^{\circ} \mathrm{C}$ dengan $\mathrm{pH} 7$ dengan kelembapan $76-82 \%$.

\section{SIMPULAN}

Berdasarkan Hasil penelitian jenis jamur yang dapat dikonsumsi yakni Poliotha mutabilis, Coprinus comatus, Schizophyllum commune, Pleorotus ostreatus, Volvarielle volvacea dan Auricularia polytricha. Jenis jamu beracun yakni: Hidnum repandum, Trametes versicolor, Mycena hiemalis, Lentinus conatus, Marasmius remealis, Dacryopinax spathularia, Polyporus squamosus, Pycnoporus annabarinus, Fuligo septica dan Cortinarius sanguenius.

\section{SARAN}

\section{UCAPAN TERIMA KASIH}

Pada pelaksanaan penelitian ini tim peneliti mengucapkan terimakasih kepada pimpinan STKIP PGRI Lubuklinggau yang telah mendanai dan memfasilitasi penelitian ini.

\section{DAFTAR PUSTAKA}

[1] Syafrizal, S. 2014. Inventaris jamur Makroskopis di Hutan Adat Kantuk dan Implementasina dalam pembuatan Flipbook. Tesis, Pendidikan biologi, Universitas Tanjungpura, 4

[2] Darwis, W. Desnalianif, Dan Supriati, R. 2011. Inventaris jamur yang dapat dikonsumsi dan Beracun yang terdapat di sekitar hutan dan Sekitar Desa TanjungbKemuning Kaur Bengkulu. Jurnal Ilmiah 7 (2), 1-8

[3] Lincoff, G.H. 1981. The Audubon Society Field Guide to North American Mushrooms. Alfred A.Knopf Press. New York. 
Jurnal Biologi dan Pembelajarannya, Vol 6 No 2, Oktober 2019. Pp: 15-16

e-ISSN: $2406-8659$

[4] Chew, K.S. 2008, Early Onset Muscarinic Manifestations after Wild Mushroom Ingestion, Emergency.

[5] Medicine Department, School of Medical sciences, University Sains Malaysia. Malaysia. 